\title{
The World Optical Depth Research and Calibration Center (WORCC) quality assurance and quality control of GAW-PFR AOD measurements
}

\author{
Stelios Kazadzis, Natalia Kouremeti, Stephan Nyeki, Julian Gröbner, and Christoph Wehrli \\ Physikalisch-Meteorologisches Observatorium Davos, World Radiation Center (PMOD/WRC) Dorfstrasse 33, \\ 7260 Davos Dorf, Switzerland
}

Correspondence: Stelios Kazadzis (stelios.kazadzis@pmodwrc.ch)

Received: 10 October 2017 - Discussion started: 23 October 2017

Revised: 19 December 2017 - Accepted: 1 January 2018 - Published: 2 February 2018

\begin{abstract}
The World Optical Depth Research Calibration Center (WORCC) is a section within the World Radiation Center at Physikalisches-Meteorologisches Observatorium (PMOD/WRC), Davos, Switzerland, established after the recommendations of the World Meteorological Organization for calibration of aerosol optical depth (AOD)-related Sun photometers. WORCC is mandated to develop new methods for instrument calibration, to initiate homogenization activities among different AOD networks and to run a network (GAW-PFR) of Sun photometers. In this work we describe the calibration hierarchy and methods used under WORCC and the basic procedures, tests and processing techniques in order to ensure the quality assurance and quality control of the AOD-retrieved data.
\end{abstract}

\section{Introduction}

Aerosols in the atmosphere, through direct and indirect effects, mainly result in a cooling contribution to the global radiation balance (IPCC, 2013). The parameter that describes their integrated optical attenuation is the aerosol optical depth (AOD), which can be derived by measurements of the sunlight transmittance (WMO, 2016b). AOD has been used in case studies and local studies in order to characterize aerosols and assess atmospheric pollution and the aerosolrelated radiative forcing.

Atmospheric extinction of sunlight has been studied for at least 250 years by P. Bouger (http://glossary. ametsoc.org/wiki/Bouguer_s_law). Linke (1942) studied turbidity, Angström (1929) studied extinction power law and
Junge (1952) studied the relationship between particle volume and aerosol number size distribution. They have mainly set the theoretical basis for studying aerosol extinction. However, Volz (1959) have developed a Sun photometer that is able to measure atmospheric turbidity at different wavelengths using filters, used in the first US (Volz, 1969) and the first European (Flowers, 1969) networks of turbidity measurements. Since then various sites have included AOD measurements in their monitoring schedules, constructing longterm series of AOD (e.g., Barreto et al., 2014; Weller and Gericke, 2005; Nyeki et al., 2012). Most of these measurements are site specific, with little relevance to long-term trend analysis on a global scale. However, more recently, several multiyear spatial studies (Holben, 2001; Che et al., 2015; Mitchell et al., 2017) have been conducted.

The World Meteorological Organization (WMO) instigated the Global Atmosphere Watch (GAW) program in 1989 as a successor to the Background Air Pollution Monitoring Network (BAPMoN). In 1993 (WMO, 1993) it was recommended that AOD measurements, conducted previously under BAPMoN, should be discontinued until new instruments, methods and protocols could be established to collect AOD data of known and assured quality. Based on a recommendation by GAW experts, the World Optical Depth Research Calibration Center (WORCC) was established in 1996 at the PMOD/WRC in Switzerland. WORCC has since been advised by the GAW Scientific Advisory Group for Aerosols. Fifteen existing GAW stations were chosen for the deployment and operation of $12 \mathrm{~N}$-type precision filter radiometers (PFRs; manufactured by PMOD/WRC) (Wehrli, 2000), pro- 
vided by the Swiss Government. WORCC was assigned the following tasks:

- development of a radiometric reference for spectral radiometry to determine AOD

- development of procedures to ensure worldwide homogeneity of AOD observations

- development of new instrumentation and methods for AOD

- implementation of a pilot network for AOD at GAW global observatories including quality control and quality assurance of data called GAW-PFR

- training operators to use and maintain AOD instruments.

There are different global networks measuring AOD, mainly distinguished by the different instruments used in each of them. The AErosol RObotic NEtwork (AERONET) (Holben et al., 1998, 2001) (http://aeronet.gsfc.nasa.gov/) is the major global network with central calibration facilities in the USA, France and Spain. The sky radiometer network (SKYNET) aerosol network (Takamura and Nakajima, 2004; Campanelli, 2004) is an observational network dedicated to aerosol-cloud-radiation interaction research studies. The Australian AOD network includes 22 stations (Mitchell et al., 2017). The Chinese Aerosol Remote Sensing network (CARSNET), reporting AOD measurements for 50 sites, representing remote, rural and urban areas (Che et al., 2015). In addition, national, regional and global networks such as the French component of AERONET, PHOTONS (Goloub et al., 2007), the Iberian Network for aerosol measurements (RIMA) (Toledano et al., 2011) and Aerosol Canada (AEROCAN) (Bokoye et al., 2001) have contributed to AOD climatology studies.

The Swiss-built PFR (Wehrli in WMO, 2005) has been operating continuously at 15 GAW stations and at another 23 associated ones worldwide. The PFR is expressly designed to make automated long-term observations at four wavelengths (368, 412, 500 and $862 \mathrm{~nm})$. Several studies using data from the GAW-PFR network have been published mainly focusing on long-term changes in AOD (e.g., Ruckstuhl et al., 2008; Nyeki et al., 2012, 2015). In addition to these studies, GAWPFR aims to provide intercomparison information between networks by overlapping at selected sites

PFR instruments of the GAW-PFR network currently overlap with AERONET, SKYNET, CARSNET, the Australian Network and other Sun photometers at several sites. As there is a need for a common strategy to merge the various network observations into a global data set, the WMO-GAW scientific advisory group for aerosols recommended that GAW will have to collaborate with existing major networks to develop this strategy, implementing and developing, together with satellite agencies, a system for integrating global AOD observations. Towards the same goal, WORCC organizes a filter radiometer comparison every 5 years with a number of reference AOD-measuring instruments from different networks. The last comparison was held in 2015 with the participation of 30 instruments (WMO, 2016a). In this work, we present the research activities of WORCC and more specifically the calibration hierarchy, the quality assurance and quality control of the GAW-PFR network AOD measurements.

The characterization and calibration of the PFR instruments, together with the quality assurance and quality control of the measurements, is WORCC's major task. In this work, we summarize the calibration procedures and hierarchy since the GAW-PFR network was established 17 years ago and the quality assurance and control of the data that the instruments provide.

\section{Calibration principles and hierarchy}

AOD is a dimensionless quantity that cannot be measured directly. It can be retrieved from atmospheric transmission measurements and cannot be directly linked to any SI (International System of Units) reference since the atmospheric transmission is also a relative factor related to the direct solar irradiance $(I)$ at a particular wavelength $(\lambda)$ and $I(\lambda)$ at the surface and at the top of the atmosphere $I_{o}(\lambda, r)$, where $r$ is the Sun-Earth distance. As a consequence, transmission can be measured in any unit and in the case of Sun photometers, the instrument voltage signal $V(\lambda)$ and the signal at the top of the atmosphere (extra-terrestrial value $V_{\mathrm{o}}(\lambda, r)$ ) can be written based on the Beer-Lambert law:

$V(\lambda, m, R)=V_{\mathrm{o}}(\lambda) e^{-m \delta(\lambda)} R^{-2}+\varepsilon$

where $V_{\mathrm{o}}$ is the exoatmospheric signal at wavelength $\lambda$ and standard Sun-Earth distance of 1 astronomical unit, $m$ is the optical air mass along the line of sight to the Sun, $\delta$ is the total optical depth, $R$ is the Sun-Earth distance in astronomical units, and $\varepsilon$ accounts for the circumsolar sky radiance in the field of view of the Sun photometer. The total optical thickness $m \times \delta$ includes several terms describing the extinction by different atmospheric components: molecular scattering, gas absorption and aerosol extinction. Then in order to calculate the AOD we use the following:

$\tau_{\mathrm{aer}}=\frac{\ln \left(V_{\mathrm{o}}\right)-\ln (V)}{m}-\tau_{\mathrm{rt}}$,

where $\tau_{\text {aer }}$ is the AOD, $m$ is the optical air mass and $\tau_{\mathrm{rt}}$ is the attenuation due to Rayleigh scattering and other trace gases for cloudless conditions. Using Eq. (2), we conclude that an error of $1 \%$ in $V o(\lambda)$ results in an AOD of 0.01 for an air mass equal to 1 .

According to WMO (2005), as traceability is not currently possible based on physical measurement systems, the initial form of traceability will be based on difference criteria. That 
is, at an intercomparison or co-location, traceability will be established if the difference between the AOD of one network and another is within specific limits. Those limits for finite field-of-view instruments have been set (WMO, 2005) to optical depths of $0.005+0.01 \mathrm{~m}^{-1}$ and the acceptable traceability is when $95 \%$ of the absolute AODs are within those limits. So requiring $95 \%$ uncertainty (U95) within optical depths of $\pm 0.005+0.01 \mathrm{~m}^{-1}$, where the first term $(0.005)$ is linked to instrument uncertainties (signal linearity, Sun pointing, temperature effects, processing, etc.) and the second term to a calibration uncertainty of $1 \%$.

The WORCC standard group of three PFRs (defined as the "PFR triad") was established in 2005 by WORCC in order to fulfill the WMO mandate on "homogenization of global AOD through provision of traceability to the World Standard Group (WSG) of spectral radiometers for contributing networks at co-located sites and/or periodic international filter radiometer comparisons, and further standardization of evaluation algorithms". Since 2005, five different wellmaintained instruments have been used as part of the PFR triad. Figure 1 shows the long-term (12 years) comparison of the PFR triad instruments.

The long-term relative stability of each of the five PFRs that were part of the triad is presented in Fig. 1. The left panel shows the $1 \mathrm{~min}$ AOD PFR differences, compared using the WMO-U95 criterion at all four PFR-measuring wavelengths. It should be noted that all instruments measure at WORCC in Davos, Switzerland. They are mounted on the same solar tracking system and their signal is processed using a common processing algorithm. In the 12 years of $1 \mathrm{~min}$ measurement data, more than $99 \%$ of retrieved AOD lies within the U95-WMO criterion, at all wavelengths. The right panel of Fig. 1 shows the individual instrument comparisons with the mean triad AOD in more detail. As shown, all differences are well within \pm 0.005 with small shifts for different PFRs and particular wavelengths.

In order to continuously check and maintain the triad stability we have defined a calibration protocol including instruments frequently performing Langley calibrations at high-altitude stations. For this calibration method (Holben et al., 1998; Michalsky et al., 2001) the main requirement is the stability of AOD during the measurement Langley periods (half days). Theoretically, this can be achieved anywhere, but in practice AOD is variable during the day, so the current practice is to perform such measurements at highaltitude locations where AOD is very low; thus its variability is very small on an absolute level. Since 2003, Mauna Loa, Hawaii, USA (MLO, $19.5^{\circ} \mathrm{N}, 155.6^{\circ} \mathrm{W}, 3397 \mathrm{~m}$ a.s.l.), Izana, Tenerife, Spain (IZO, 28.3 $\mathrm{N}, 16.5^{\circ} \mathrm{W}, 2370 \mathrm{~m}$ a.s.l.) and Jungfraujoch, Switzerland (JFJ, $3580 \mathrm{~m}$ a.s.1. $46.5^{\circ} \mathrm{N}$, $7.9^{\circ} \mathrm{E}$ ), have mainly been used for such Langley calibrations. PFR instruments have been permanently deployed at these stations for certain periods since 2003, and approximately every 6 months, one of these instruments is returned to WORCC to perform synchronous measurements in par- allel with the triad. Table 1 lists the details of these visits. For each period it describes the current status of the PFR instruments of the triad, the transferred instrument performing the Langley plots and the Langley plot measurement location and period.

The determination of $V o$ with the Langley calibration method using a 6-month period of measurements requires high accuracy and quantification of the introduced uncertainties. Using a defined calibration method, the $V o$ accuracy can be traced back to the variability of the $V o$ determination and is related to the instrument precision and the procedures. Practically, the long-term stability of $V o$ is mainly related to degradation/changes in the transmission of the optical interference filters, or hardware-related failures/changes that are linked to changes in the instrument signal.

WORCC Langley algorithms use half-days to determine $V o$ values. The main requirements for accepting a half-day Langley determination of $V o$ are the AOD stability, the signal stability and the statistics of the retrieved signal versus air mass linear regression using specific air mass limitations. An example of accepted Langley (half-day) measurements for a 6-month period at MLO is shown in Fig. 2.

Figure 2 shows 95 Langley diagrams/days that have been used to analyze Langley calibration results and related uncertainties. The mean $\ln (V o)$ calculated for this period at $500 \mathrm{~nm}$ was 1.343 , the standard deviation was 0.002 and the 5th and 95th percentiles were 1.340 and 1.346, respectively. The distribution of $\ln (V o)$ values is also shown with the statistics for mean AOD values $(0.010-0.015$ at $500 \mathrm{~nm})$. The distribution and the normal distribution are shown in the upper-left subplot of Fig. 2.

Based on Eq. (1) the AOD absolute uncertainty, $\delta \mathrm{AOD}_{V o}$ that is related only to the Langley calibration factor, using Eq. (2), equals $\frac{\delta \ln (V o)}{m}$ where $\delta \ln (V o)$ is the uncertainty in $\ln (V o)$. The uncertainty of $\ln (V o)$ can be described by the coefficient of variation (standard deviation/mean, CV) or in the case of a normal distribution by the standard error (standard deviation divided by the square root of the number of measurements, SE). For the particular example in Fig. 2, the calibration uncertainties are shown in Table 2.

As described above, this uncertainty is directly related to the calculated $\delta \mathrm{AOD}_{V o}$ uncertainty and is equal to $\delta \ln (V o)$ when $m=1$. In Fig. 3, Vo values at 500 and $865 \mathrm{~nm}$ are shown as a function of time for measurements of the PFR instrument N06 that measured at Davos from 2000 to 2005 and at IZO from 2005 to 2016. In addition, the evolution of the $\mathrm{SE}$ is shown.

Each of the data points in Fig. 3 represents average $V o$ values at the end of the averaging period which varies between 3 and 6 months. PFR N06 has exhibited good stability since 2000. All instrument filters have not changed more than 0.1 in $V o$ units, which corresponds to maximum changes in AOD of $\sim 0.02$ when $m=1$. However, the $412 \mathrm{~nm}$ filter is an exception which has apparently degraded since 2009 . The maximum changes in AOD (at $m=1$ ) were $\sim 0.05$ from 

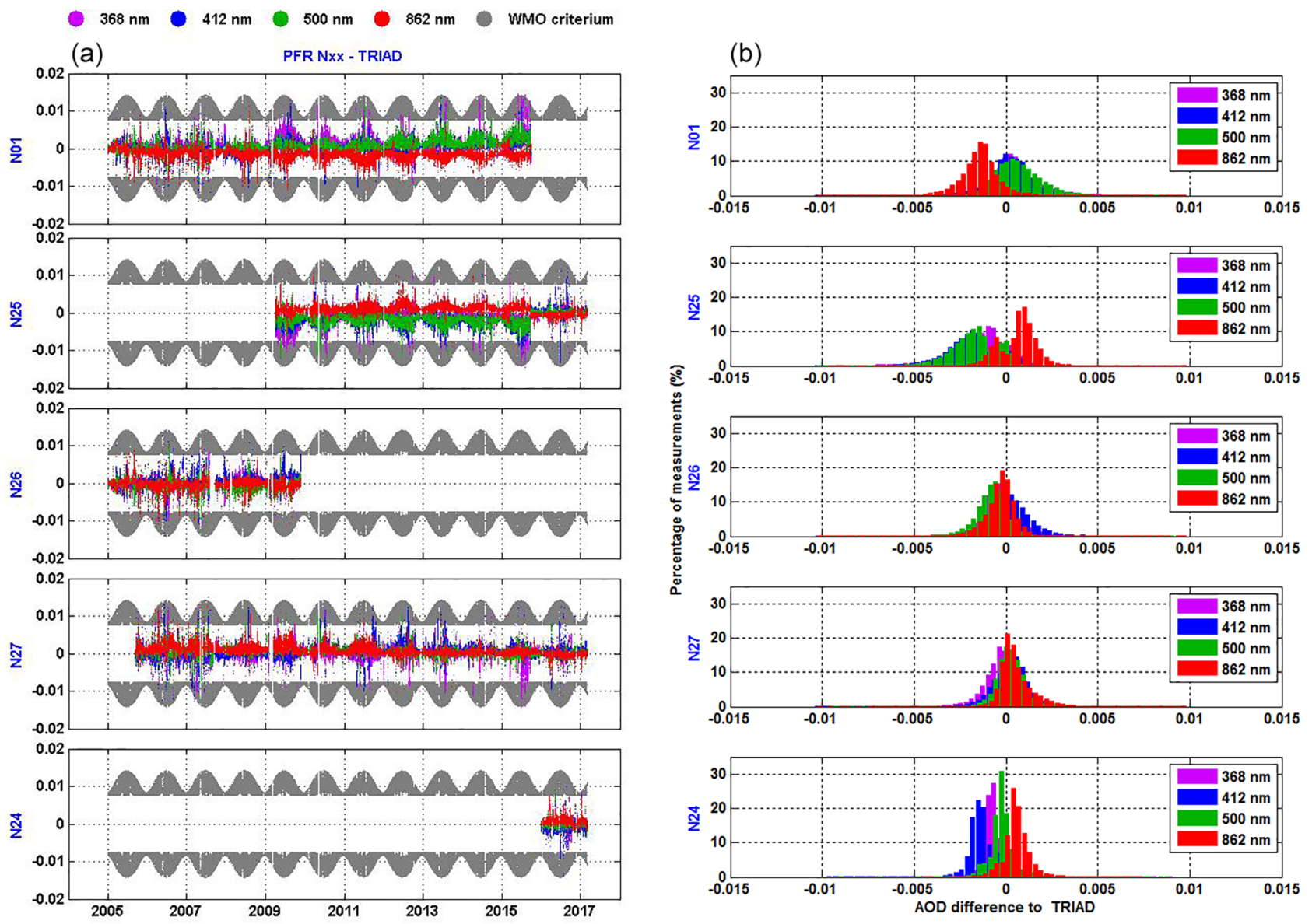

Figure 1. (a) Difference between each PFR with the mean of the PFR triad at the four PFR wavelengths. Grey areas represent the WMO-U95 limits. (b) Frequency distribution of these differences for the four measuring wavelengths.

Table 1. Details of PFR triad Langley calibration measurements.

\begin{tabular}{|c|c|c|c|c|c|c|c|}
\hline \multirow{2}{*}{$\begin{array}{l}\text { Year } \\
2003\end{array}$} & \multirow{2}{*}{\multicolumn{2}{|c|}{$\begin{array}{ll} & \text { Triad } \\
& \\
\text { N01 } & \text { N26 }\end{array}$}} & \multirow{2}{*}{$\frac{\mathrm{ad}}{26}$} & \multirow{2}{*}{$\begin{array}{l}\begin{array}{l}\text { Comparison } \\
\text { reference }\end{array} \\
\mathrm{N} 26\end{array}$} & \multirow{2}{*}{$\begin{array}{l}\begin{array}{l}\text { Calibration } \\
\text { type }\end{array} \\
\text { MLO-Langley }\end{array}$} & \multicolumn{2}{|c|}{ Comparison period } \\
\hline & & & & & & 1 Mar 2000 & 31 May 2003 \\
\hline 2005 & N01 & N26 & $\mathrm{N} 27$ & N27 & MLO-Langley & 1 Sep 2005 & 31 Dec 2005 \\
\hline 2009 & N01 & $\mathrm{N} 26$ & $\mathrm{~N} 27$ & $\mathrm{~N} 25$ & IZO-Langley & 1 Apr 2009 & 31 Jun 2009 \\
\hline \multirow[t]{2}{*}{2010} & N01 & $\mathrm{N} 25$ & $\mathrm{~N} 27$ & $\mathrm{~N} 24$ & JFJ-Langley & 1 Jan 2010 & 31 Jan 2010 \\
\hline & N01 & $\mathrm{N} 25$ & $\mathrm{~N} 27$ & $\mathrm{~N} 22$ & MLO-Langley & 1 Jun 2010 & 31 Jun 2010 \\
\hline 2011 & N01 & $\mathrm{N} 25$ & $\mathrm{~N} 27$ & $\begin{array}{l}\text { mean of } \\
\text { N01, N25, N27 }\end{array}$ & & & \\
\hline 2012 & N01 & N25 & $\mathrm{N} 27$ & $\mathrm{~N} 21$ & IZO-Langley & 1 Oct 2012 & 31 Dec 2012 \\
\hline 2013 & N01 & $\mathrm{N} 25$ & $\mathrm{~N} 27$ & N06 & IZO-Langley & 1 Aug 2013 & 31 Aug 2013 \\
\hline 2014 & N01 & $\mathrm{N} 25$ & $\mathrm{~N} 27$ & $\begin{array}{l}\text { mean of } \\
\text { N01, N25, N27 }\end{array}$ & & & \\
\hline \multirow[t]{3}{*}{2015} & N01 & $\mathrm{N} 25$ & $\mathrm{~N} 27$ & N06 & IZO-Langley & 21 Sep 2015 & 28 Sep 2015 \\
\hline & N01 & $\mathrm{N} 25$ & $\mathrm{~N} 27$ & $\mathrm{~N} 21$ & IZO-Langley & 21 Sep 2015 & 28 Sep 2015 \\
\hline & N01 & $\mathrm{N} 25$ & $\mathrm{~N} 27$ & $\mathrm{~N} 24$ & MLO-Langley & 21 Sep 2015 & 28 Sep 2015 \\
\hline 2016 & $\mathrm{~N} 24$ & N25 & $\mathrm{N} 27$ & N06 & IZO-Langley & 01 Oct 2016 & 31 Dec 2016 \\
\hline 2017 & $\mathrm{~N} 24$ & $\mathrm{~N} 25$ & $\mathrm{~N} 27$ & $\mathrm{~N} 21$ & IZO-Langley & 17 Mar 2017 & 14 Apr 2017 \\
\hline
\end{tabular}



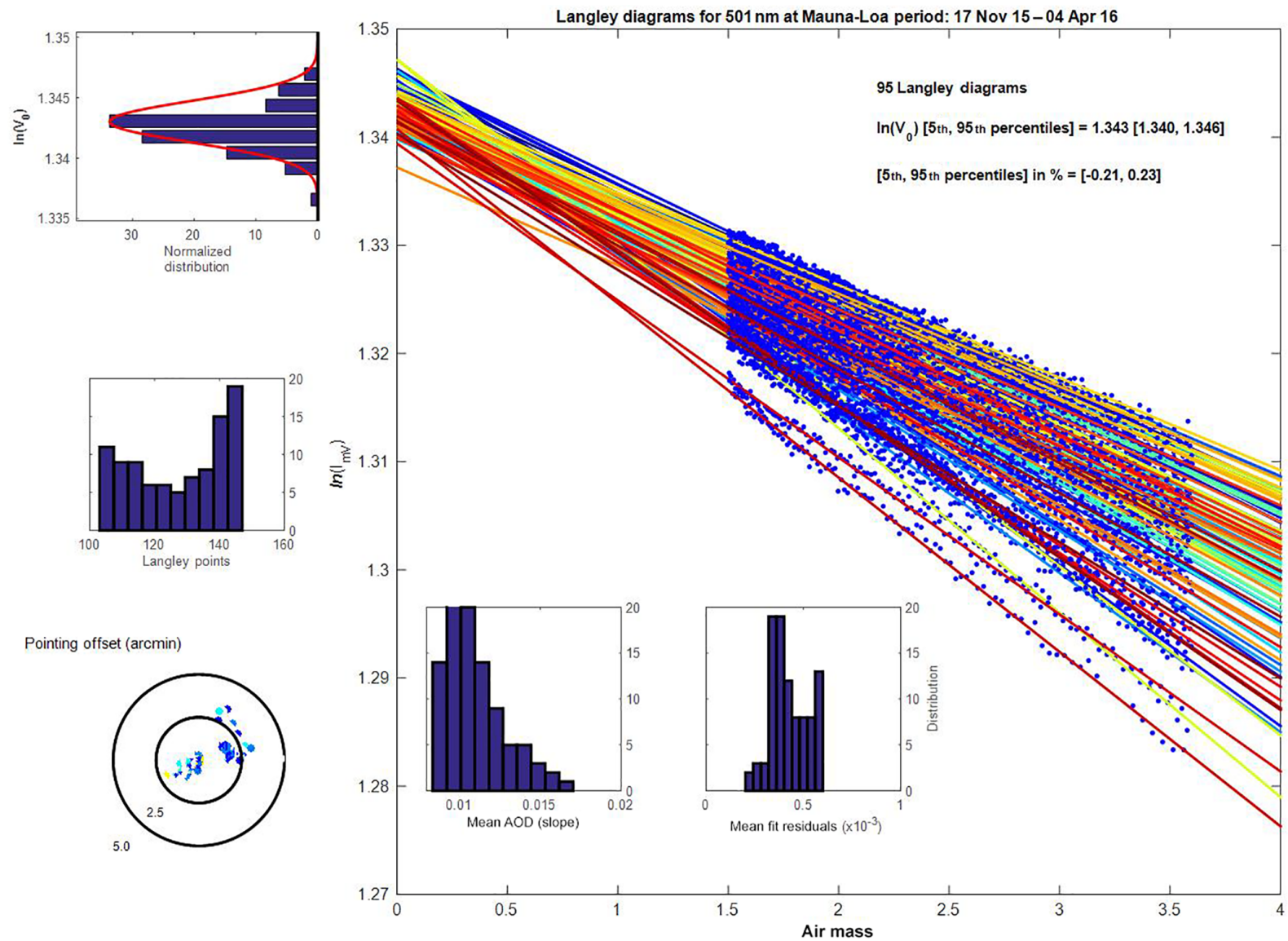

Figure 2. Langley plots for Mauna Loa observatory from November 2015 to April 2016.

Table 2. Calibration uncertainties derived from 6 months of Langley calibration measurements shown in Fig. 2.

\begin{tabular}{lrrrrr}
\hline $\begin{array}{l}\text { PFR } \\
\text { wavelength } \\
(\mathrm{nm})\end{array}$ & $\begin{array}{r}\text { Number of } \\
\text { Langley plots } \\
(\mathrm{N})\end{array}$ & $\begin{array}{r}\text { Mean } \\
(\ln (V o))\end{array}$ & $\begin{array}{r}\text { Standard } \\
\text { deviation }\end{array}$ & $\begin{array}{r}\delta \ln (V o)(\mathrm{CV}) \\
m=1\end{array}$ & $\begin{array}{r}\delta \ln (V o)(\mathrm{SE}) \\
\text { (norm. distr.) } \\
m=1\end{array}$ \\
\hline 368 & 75 & 1.438 & 0.002 & 0.0013 & 0.00015 \\
412 & 93 & 1.308 & 0.002 & 0.0015 & 0.00015 \\
500 & 95 & 1.343 & 0.002 & 0.0014 & 0.00014 \\
863 & 56 & 1.276 & 0.001 & 0.0007 & 0.00009 \\
\hline
\end{tabular}

2009 to 2016. It has to be noted that all the above-described changes have been taken into account in order to calculate the corresponding AOD for the individual periods. Results in Fig. 3 illustrate the stability of PFR instruments over time. The very low filter response changes over long-term periods increase the statistical validity of each 6-month Langley calibration period.

\section{GAW-PFR network}

A primary task of WORCC is the implementation of a global trial network at selected GAW stations with the objective of demonstrating that PFR instruments, together with standard calibration techniques and quality assurance procedures, can be used to determine AOD with a precision adequate for the fulfilment of the objectives of GAW (WMO, 2001). In addition, it is intended that long-term high-resolution AOD measurements are conducted and analyzed at selected GAW locations.

The locations, together with their characteristics in terms of aerosol sources and their period of measurements, are described in Table 3. Bratts Lake and Mace Head measurements were unfortunately discontinued in 2012 and 2015, respectively, due to logistical aspects. However, Valentia (Ire- 


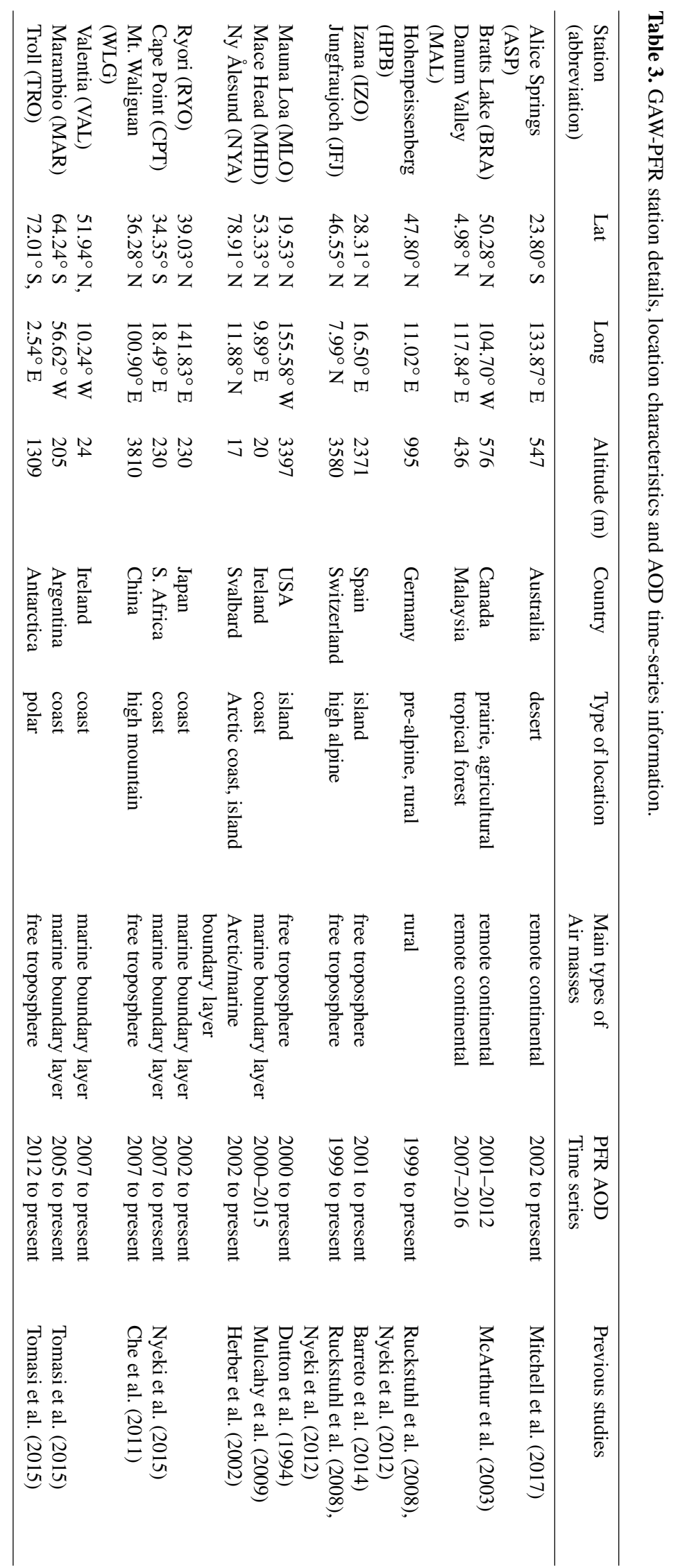




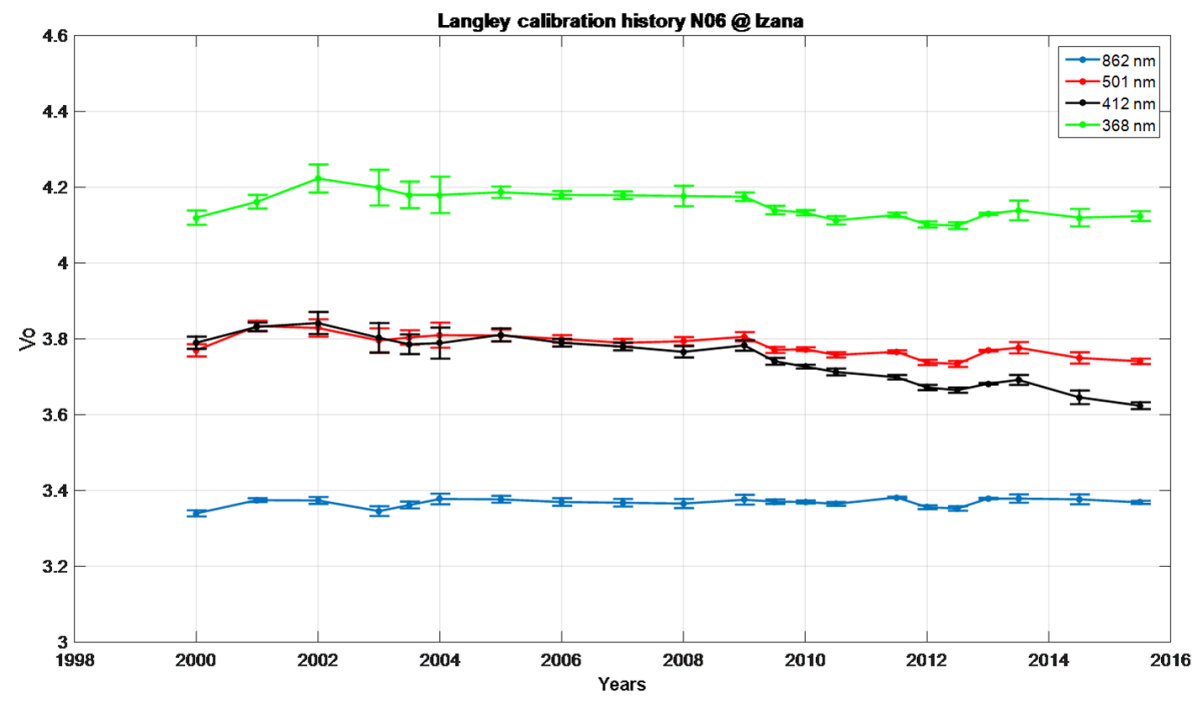

Figure 3. Long-term Vo values for PFR-N06 at Davos and IZO for the four PFR channels. Bars indicated the standard error.

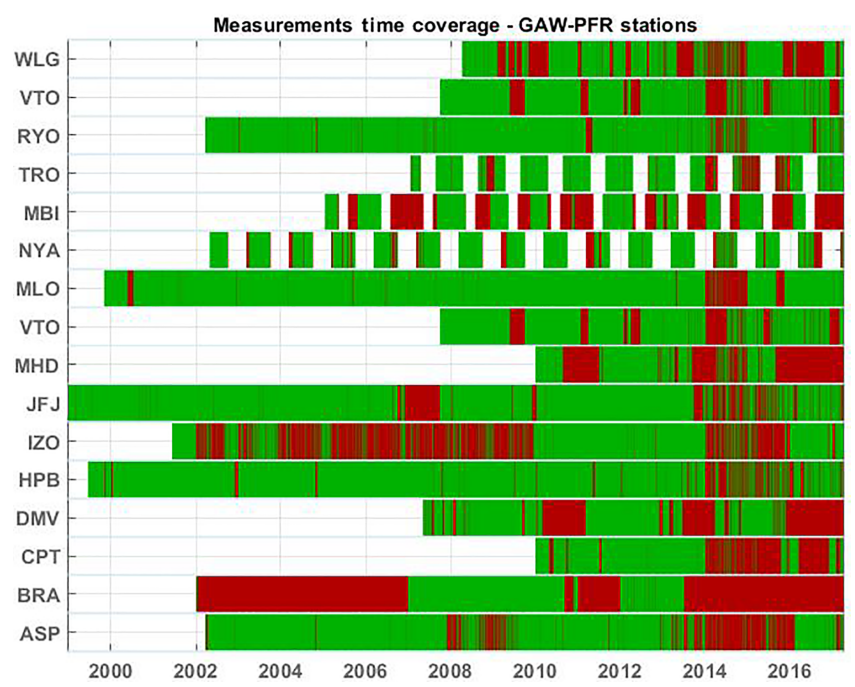

Figure 4. Data coverage of GAW-PFR stations. Green indicates periods with data availability and red indicates missing data.

land), Troll (Antarctica) and Marambio (Argentina) have since been added to the core of GAW-PFR stations.

In addition to the core GAW-PFR instruments, 30 other locations exist that perform AOD measurements using PFR instruments belonging to individual users and institutes. An overview of data flow and availability for every location is shown in Fig. 4.

At high-latitude locations such as Troll and Ny Ålesund, AOD measurements can only be performed during part of the year due to the luck of direct Sun. Big gaps (red colors) are linked to instrument damage (e.g., MHD, DMV and CPT) due to various factors (corrosion, lightning etc.).
Smaller (red) gaps are due to instrument recalibrations through transfer and measurements in parallel with the PFR triad at Davos, Switzerland.

\subsection{Instrument calibrations}

Instruments are regularly calibrated (every 1 to 2 years, depending on instrument-related and logistical aspects). The calibration of the filter radiometer has to be assured with an uncertainty of $\pm 1 \%$ in order to achieve the required AOD uncertainty within the U95-WMO limits. Qualityassured AOD data can only be obtained when pre- and postdeployment calibration constants are available. That means that AOD data for a certain location and period can only be considered as final after the recalibration of the instrument, which is performed at the end of the specific period.

Postcalibrations can be obtained by different methods:

\subsubsection{WORCC calibration certificate}

The WORCC calibration certificate is obtained by instruments/stations that have their PFR calibrated at Davos, against the WORCC triad. Polar and high-altitude stations are often set for calibration annually during polar night/longest night periods. For other stations, a recalibration should be performed every 12 to 24 months. This method implies that preparation of the final version of the AOD data might be postponed by 1 to 2 years. Comparison of each of the instruments with the triad is performed based on the WMO criteria for AOD intercomparisons. The intercomparison lasts for at least 5 cloudless days.

The extraterrestrial calibration constants of an instrument $x, V_{0 x R}$ are determined by using $1 \mathrm{~min}$ measurements $S_{i x}$ of the instrument to be calibrated and synchronous measurement $S_{i R}$ of the reference (mean of the three triad PFRs) in- 

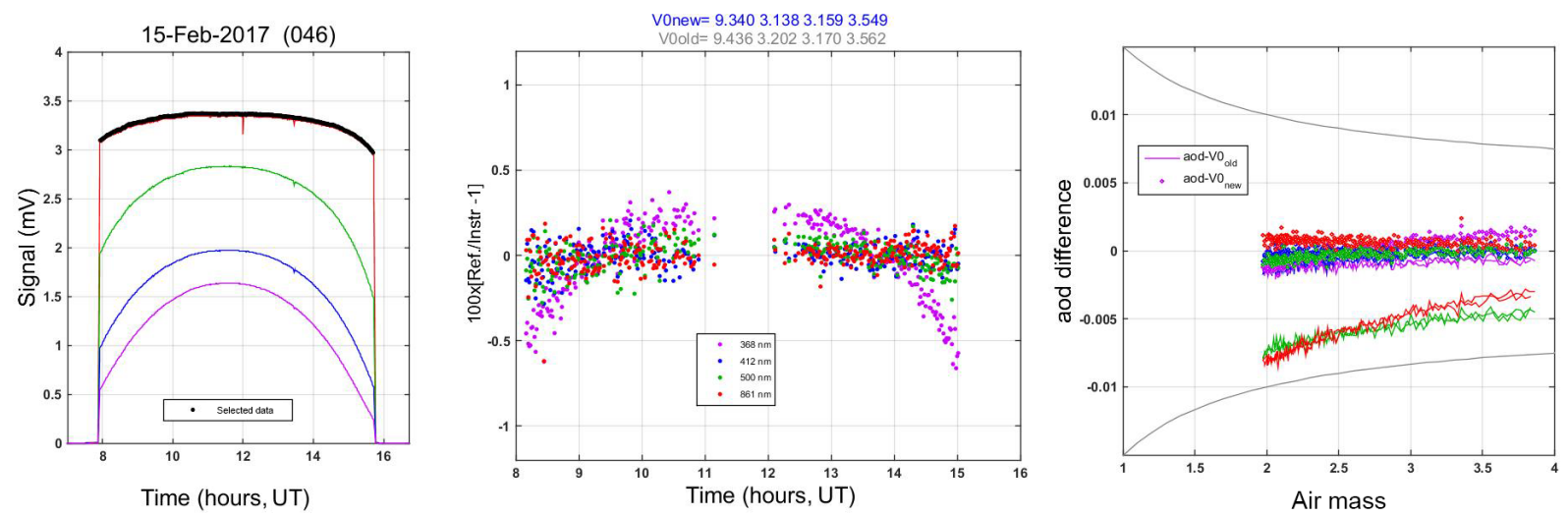

Figure 5. Calibration of an instrument against the triad: (a) measurement signals at four wavelengths, (b) comparison of instrument signals, (c) differences between instrument- and triad-retrieved AOD using the old and the new calibration $V_{0 x R}$.
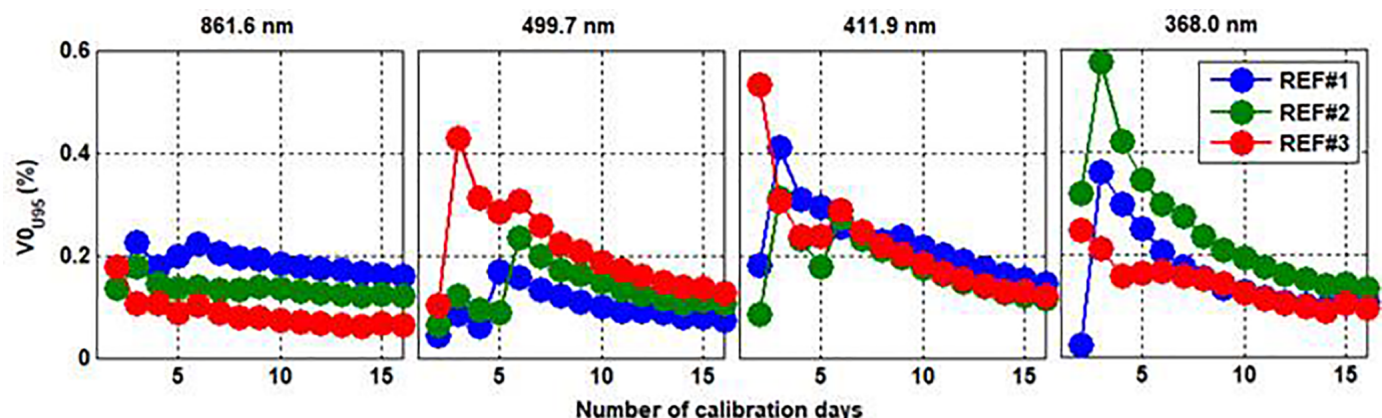

Figure 6. Graphs of $V_{0_{\mathrm{U} 95}}$ calculated over an extended calibration period of 35 days for a PFR instrument measuring against each of the three triad instruments for the four PFR wavelengths.

strument.

$V_{0 x R}=\frac{1}{N} V_{0 R} \sum_{n=1}^{N} \frac{S_{i x}}{S_{i R}}$

The daily calibration constants $V_{0 x R}$, according to (Eq. 4), are determined for days on which a number $(N \geq 120)$ of solar measurements unobstructed by clouds were collected. Comparing the instrument measurement signal to that of the triad, a new $V_{0 x R}$ is calculated and compared with the last one used. Details of such an analysis for a single day are shown in Fig. 5. Instrument signals are shown in Fig. 5a, then the percentage differences of $1 \mathrm{~min}$ data are calculated for all four wavelengths in Fig. 5b. An example of the calculated AOD differences from the triad before and after the calibration is finally shown in Fig. 5c. For the specific instrument, the $V_{0 x R}$ differences for the particular day were up to $0.5 \%$ and depended on the wavelength. The impact of this difference in AOD calculation is an air-mass-dependent difference of 0.008 to 0.003 . In practice, when an instrument is calibrated against the triad, the only limitation on using the synchronous signals is the cloud presence. So, no air mass or AOD limits are included.

The average over the number of measurements over a day, values $\bar{V}_{0 x R}$ and standard deviations $\sigma_{0 x}$ of the daily mean calibration constants from each reference instrument are averaged to give the final calibration constants $V_{0 x}$ with an expanded uncertainty U95:

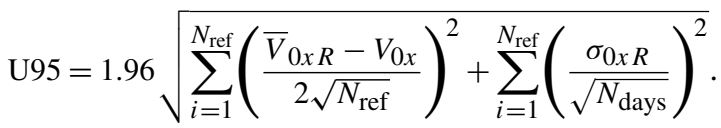

The two terms under the square root in Eq. (4) describe the combined statistical (comparison) and triad uncertainty during the calibration period.

For a normal distribution, $V 0_{\mathrm{U} 95}$ corresponds to a coverage probability of approximately $95 \%$.

The calibration is considered successful when the coefficient of variation $\mathrm{CV}=V 0_{\mathrm{U} 95} / V_{0 x}$ becomes smaller than $\pm 0.5 \%$ for all four channels of the instrument to be calibrated. This limit is typically reached after 3 to 5 days of comparison. In Fig. 6, we show $V 0_{\text {U95 }}$ calculated over an extended calibration period of 35 days for a PFR instrument measuring against the triad. For each of the four PFR wavelengths, $2 \sigma$ within the period is on the order of 0.4 to $0.9 \%$ of the mean $V o$. In addition, we have calculated the $V 0_{\mathrm{U} 95}$ in percent using Eq. (3) for the instrument under calibration with each of the three PFRs that are part of the WORCC triad. For this particular case, all wavelengths are within 

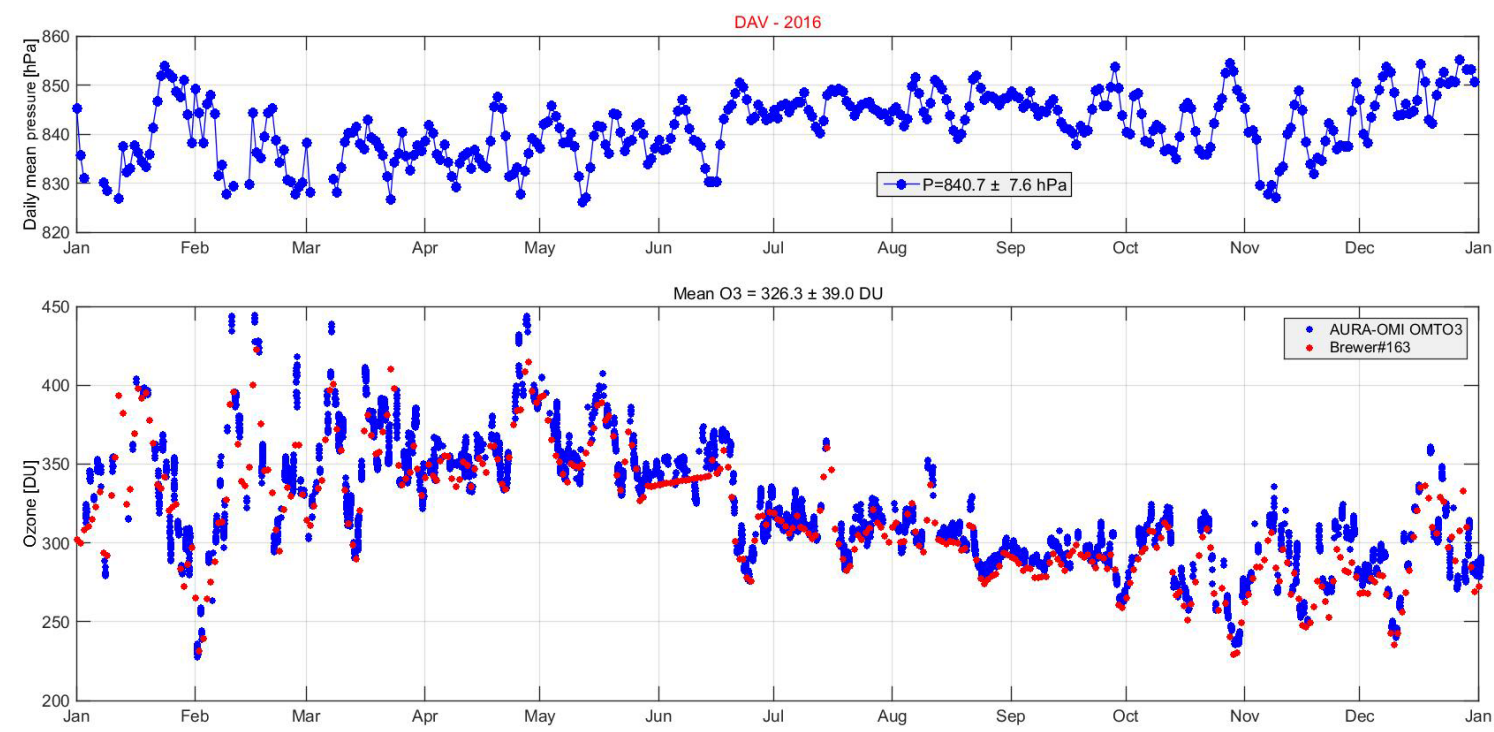

Figure 7. (a) Daily mean pressure during 2016 at Davos, Switzerland. (b) Brewer and OMI ozone values.

the limit $C V<0.4 \%$ after 3 days and after 10 days within $C V<0.2 \%$.

\subsubsection{Langley sites}

Calibrations can be obtained by statistical analysis of objective Langley plots collected in situ over an extended period of time at high-altitude (IZO, JFJ, MLO) or remote background (ASP, BRA, TRO) sites. Such an evaluation of Langley plots is routinely performed every 6 months using Langley results from 6 months before and after the anchor dates of 1 January and 1 July for each year. This method implies that annual quality-assured data can be obtained in July or August of the following year.

A smaller $(<1 \%)$ calibration uncertainty can be expected and is required for Langley sites where AOD is lower than elsewhere, and inconsistent calibration may lead to erroneous conditions such as an inverted Ångström relation (channels crossing over) or negative AOD.

Calibration $V o$ values calculated for the four AOD channels are used in order to retrieve the AOD. For the data obtained between two calibrations a calibration slope of $V o$ values is applied. If the differences between two calibrations are larger than $2 \%$ then an in situ estimate of the instrument stability is investigated from a number of in situ Langley plots or cross-calibrations between different PFR channels. This is conducted in order to determine nonlinear (over time) changes (steps) of instrumental $V o$ values.

\subsection{Quality control}

After finalizing the calibration constants to be used for the AOD retrieval, a series of QA/QC procedures are used before finalizing the AOD data.

\subsubsection{Check for ancillary data}

Ancillary data of atmospheric pressure and total ozone are needed to retrieve the Rayleigh and ozone optical thicknesses, respectively, according to Eq. (1). Atmospheric pressure measurements, required for Rayleigh scattering, should be accurate to about $3 \mathrm{hPa}$. This accuracy is readily achieved by meteorological grade barometers built into new PFR loggers. Accurate pressure data are requested from each station and compared to the daily PFR logger values. If the mean differences are larger than $\sim 3 \mathrm{hPa}$, then the atmospheric pressure is corrected and all data are reprocessed. The use of average atmospheric pressure data over a day or longer periods can lead to wavelength-dependent AOD retrieval errors and to large Ångström exponent errors.

Total column ozone values are needed to correct optical depth at $500 \mathrm{~nm}$ for ozone absorption. As the absorption coefficient at $500 \mathrm{~nm}$ is low, total ozone needs to be known to \pm 30 Dobson units or $10 \%$ of typical values, for an uncertainty of \pm 0.001 optical depths at $500 \mathrm{~nm}$. GAWPFR uses (AURA) satellite overpass observations with the Ozone Monitoring Instrument (OMI) for daily operations (McPeters et al., 2015). OMI values are validated to in situ observations for stations operating a Dobson or Brewer instrument. Where available, total column ozone may be found at the World Ozone and Ultraviolet Radiation Data Centre database (http://woudc.org/). Figure 7 shows the evolution of daily mean pressure used for the Rayleigh calculations and ozone values at Davos, Switzerland as measured in situ with a Brewer spectrophotometer and from the OMI ozone retrieval. 


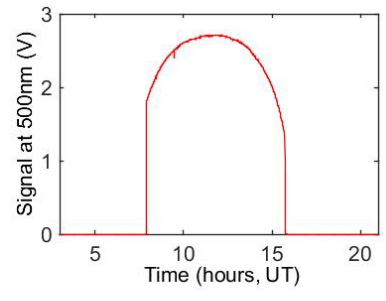

Points within 15 arcmin $100.0 \%(\mathrm{~N}=328)$

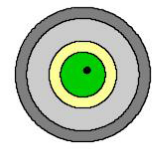

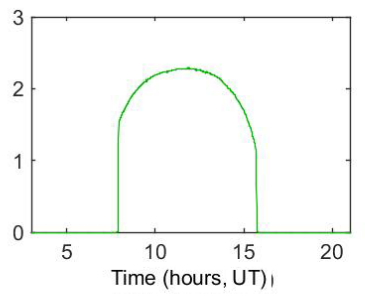

Points within 15 arcmin $100.0 \%(\mathrm{~N}=328)$

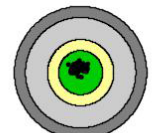

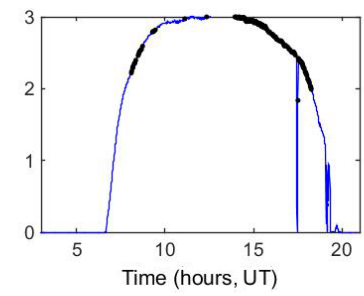

Points within $15 \operatorname{arcmin} 62.9 \%(\mathrm{~N}=606)$

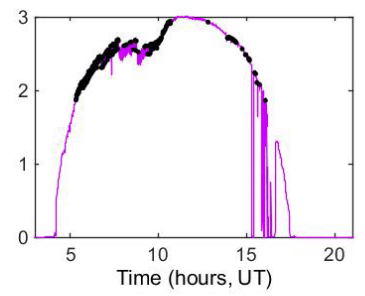

Points within $15 \operatorname{arcmin} 59.5 \%(\mathrm{~N}=496)$

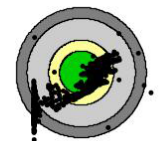

Figure 8. Example of good and bad pointing. (a) Instrument pointing, (b) instrument signal at $500 \mathrm{~nm}$. The two lower-right panels include some cloud-related signal changes after 15:00 h UT.

\subsubsection{Corrections for temperature, dark signal}

The PFR sensor temperature is checked for deviations from its active stabilized set point, indicating potential problems during extremely hot or cold ambient conditions. The PFR dark signal is checked for values $>0.25 \mathrm{mV}$, and if found on approximately $5 \%$ of days, a correction is applied. The dark signal is the mean signal when the solar elevation is less than $-6^{\circ}$, i.e., below the horizon. The temperature dependence of its PFR is based on characterization measurements in a climate chamber. Corrections are applied only in cases in which the dependence on $V o$ is more than $\pm 2 \%$ for the range from -20 to $40^{\circ} \mathrm{C}$.

\subsubsection{Sun pointing}

In order to ensure that the full solar disk is included in the field of view (FOV) of the instrument an accurate Suntracking system is required. While a PFR instrument can be readily aligned to the Sun with the required accuracy, a solarpointing monitor of the PFR is included in order to control the Sun-pointing accuracy. This monitor consists of a fourquadrant silicon detector that is illuminated through a pinhole of $1 \mathrm{~mm}$ diameter at a distance of $70 \mathrm{~mm}$. When the light is centered, all four quadrants produce equal signals. By subtracting signals from paired pixels, the sunspot can be localized (Wehrli, 2008).

Figure 8 shows four examples of perfect to bad instruments pointing at four cloudless, low aerosol concentration $(\mathrm{AOD}<0.1)$ days. The instrument pointing is shown in the upper plots. The first (from the left) case shows a perfect pointing accuracy where 328 measurements during the day are almost identical in terms of pointing direction. The second case shows when all measurements can be found inside the 15 arcmin limit. Finally, the last two cases show instruments with pointing issues where only 62.9 and $59.5 \%$ cases respectively are inside the 15 arcmin limit, and in the last case a number of measurements are outside the 25 and 30 arcmin limit.

The result of the measured signal (which has a direct impact on calculated AOD) is shown in the lower panel, where the first two days show a very smooth daily pattern, while artificial signal features can be seen in the last two cases. The use of these data will end up in an artificially overestimated AOD retrieval.

\subsubsection{Check for crossing of wavelengths}

An additional quality control check detects instances when AOD at one of the four PFR wavelengths is less than that at a higher wavelength. This quality check is mainly performed in order to detect the erroneous performance of one of the four channels. The test also becomes very important when low AOD values are measured, which is the case at a number of GAW-PFR stations. Small errors related to the calibration of one channel can be easily identified, as this results in a wavelength crossing of AOD. During evaluation of the data, the processing software tools give the opportunity to define the limits of the accepted offset for the wavelength crossing.

An example of the graphic representation of wavelength crossing is shown in Fig. 9. Based on the fact that AOD at lower wavelengths has to be at least equal to or higher than that at higher wavelengths, colored points show the correlation of pairs of AOD values at different wavelengths and black points represent the cases in which wavelength crossing occurs. The figure is composed of $703501 \mathrm{~min}$, cloudless measurements from the year 2015 as recorded at Cape Point, South Africa. For example, as many as $14.3 \%$ of data in the $412-500 \mathrm{~nm}$ panel (red-blue section) do not pass the wavelength crossing test, so they are discarded form the postprocessing analysis. 


\subsubsection{Other issues}

The spectral bandpasses of all PFR instruments have been characterized for their effective spectral wavelength and bandwidth. This is determined as the average wavelength weighted by the spectral response and equivalent width of a rectangular bandpass with equal throughput as the filter. Minimum and maximum central wavelengths (and bandwidths) that have been calculated were 367.2-367.7 (3.5-3.7), 411.8-412.6 (4.3-4.4), 500.6-501.5 (5-5.1) and 861.3-863 (5.5-5.6). These measurements were performed using illumination by a grating monochromator (Jobin Yvon HR640) with $0.6 \mathrm{~nm}$ spectral resolution. Lately, a pulsed tuneable laser system for the characterization of spectrometers and filter radiometers has been available at PMOD/WRC. Test measurements with PFR instruments did not show significant differences from the older characterization measurements.

\subsection{Cloud flagging}

As AOD measurements cannot be performed under cloudy conditions, a cloud detection algorithm is used for the PFR measurements. Three different criteria are used (Wehrli, 2008):

a. The instrument signal derivative with respect to air mass is always negative. The method has been developed and described in detail by Harrison and Michalsky (1994). For cases in which air mass values $<2$ and the influence of clouds on the noon-side of perturbations cannot be easily detected, we compare the derivative with the estimate of the clear Rayleigh atmosphere and flag it as cloudy if the rate of change is twice as much (objective method).

b. The use of a test for optically thick clouds with $\mathrm{AOD}_{500 \mathrm{~nm}}>2$.

c. The use of the Smirnov triplet measurement (Smirnov et al., 2000) by calculating AOD and looking at the signal variability for 3 consecutive minutes (triplet method).

An example of the use of these three criteria can be seen in Fig. 10, where a day with variable cloudiness at Davos is presented.

For this particular day, all three criteria are applied. In the early morning and evening, the thick-cloud criteria are applied. Then both the triplet and the objective method are applied due to variable cloudiness in front of the Sun. However, there are times during the day when only the objective method is applied (thin clouds in front of the Sun as seen in the first picture that is superimposed in Fig. 10). During the last part of the day (second picture), clouds completely disappear and cloud flagging is set to zero, which means that all three criteria are passed. It has to be noted that cloud flagging is always kept as a constant number describing which one of the three criteria or combination of criteria is valid at a certain minute.

The lower panel shows the calculation of AOD for the whole day, with obvious deviations due to cloud occurrence for the parts of the day when both criteria are fulfilled. It is interesting to see the $10: 50$ to $12: 00$ period which is a difficult period when defining the presence of clouds only with direct Sun measurements. For this particular period, even if the AOD is low, the objective method shows the presence of thin clouds in front of the Sun.

It has to be noted that final AOD data include all available measurements that have passed the quality control procedures, except the cloud-flagging ones. So, all reported AODs are available, accompanied by a flag showing which cloudflagging criteria have been assigned to the particular $1 \mathrm{~min}$ measurement.

\section{Final AOD data}

During the calibration and quality control procedure, three levels of data are defined.

Level 1: These are the raw signal data as measured by the PFR instrument at the four different channels.

Level 2: These are AOD values. The data are produced at each measuring station using standardized software including QC tests, cloud screening, Sun-tracking details and signal-to-AOD conversion using an existing calibration file. Each of the mentioned test results is characterized by a specific flag. In addition, the true solar elevation is calculated and included. None of the level 1 data are discarded.

Level 3: AOD data are re-evaluated at WORCC which includes AOD results and Ångström coefficients. Additional checks are included, such as the detection of wavelength crossing $\operatorname{AOD}\left(\lambda_{1}\right)>\operatorname{AOD}\left(\lambda_{2}\right)$, where $\lambda_{1}>\lambda_{2}$. In addition, a day-to-day visual inspection is performed in order to identify other technical issues or the possible presence of undetected clouds. For the latter, additional cloud flags are included in the final data files. Data control of level 3 data includes overviews of the instrument's tracking performance, wavelength crossing and ancillary data.

Hourly data records are prepared from quality-assured level 3 data, which are then submitted to the World Data Center for Aerosols (WDCA) hosted by the Norwegian Norsk Institutt for Luftforskning (NILU; ebas.nilu.no). Final data files include the mean, median, standard deviation and the number of $1 \mathrm{~min}$ samples used to calculate the hourly value at all four wavelengths.

In order to calculate hourly, daily and monthly statistics, we apply the following criteria:

- A minimum of 50 cloudless 1 min measurements per day are required to calculate daily statistics. In this case, we eliminate days with less than $1 \mathrm{~h}$ of sunshine. 


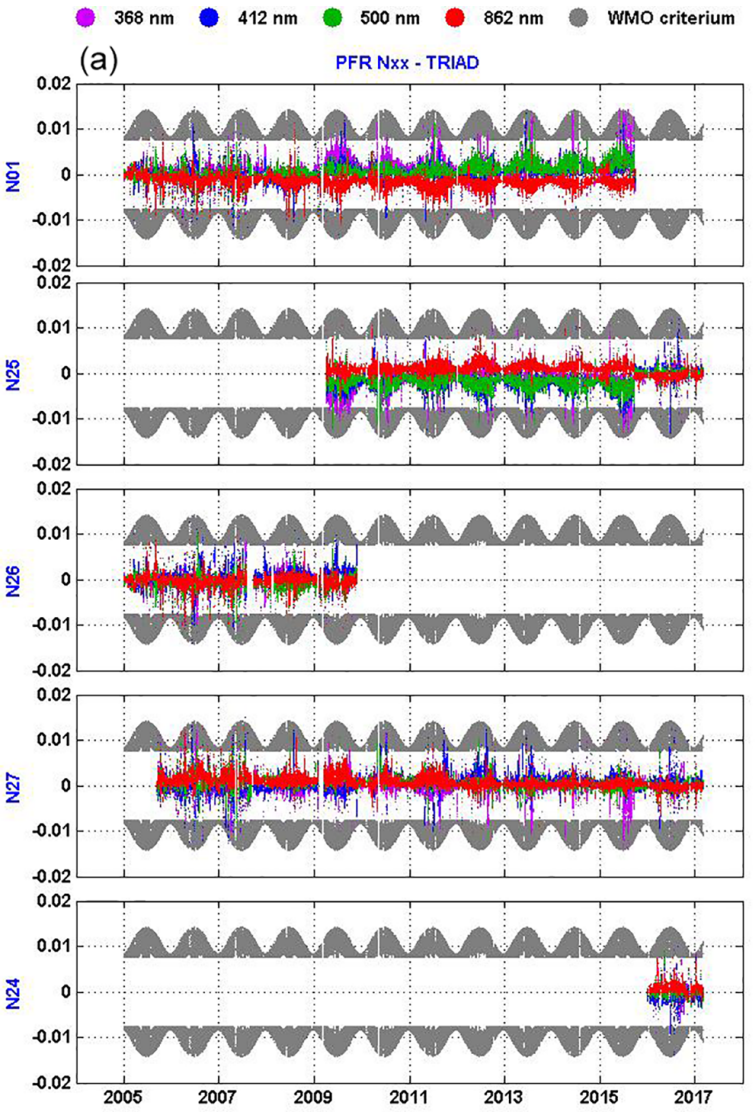

(b)
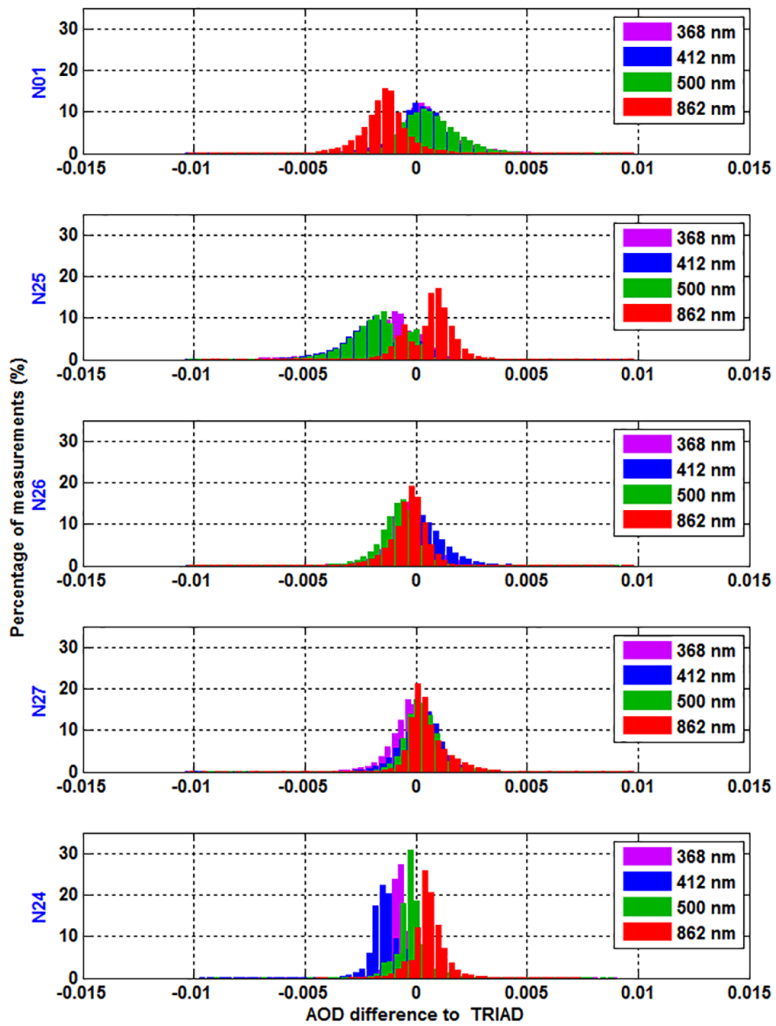

Figure 9. Correlation curves of the four PFR-measuring wavelengths. Colored points represent the data that have passed the wavelength crossing test and black ones are those that have not.

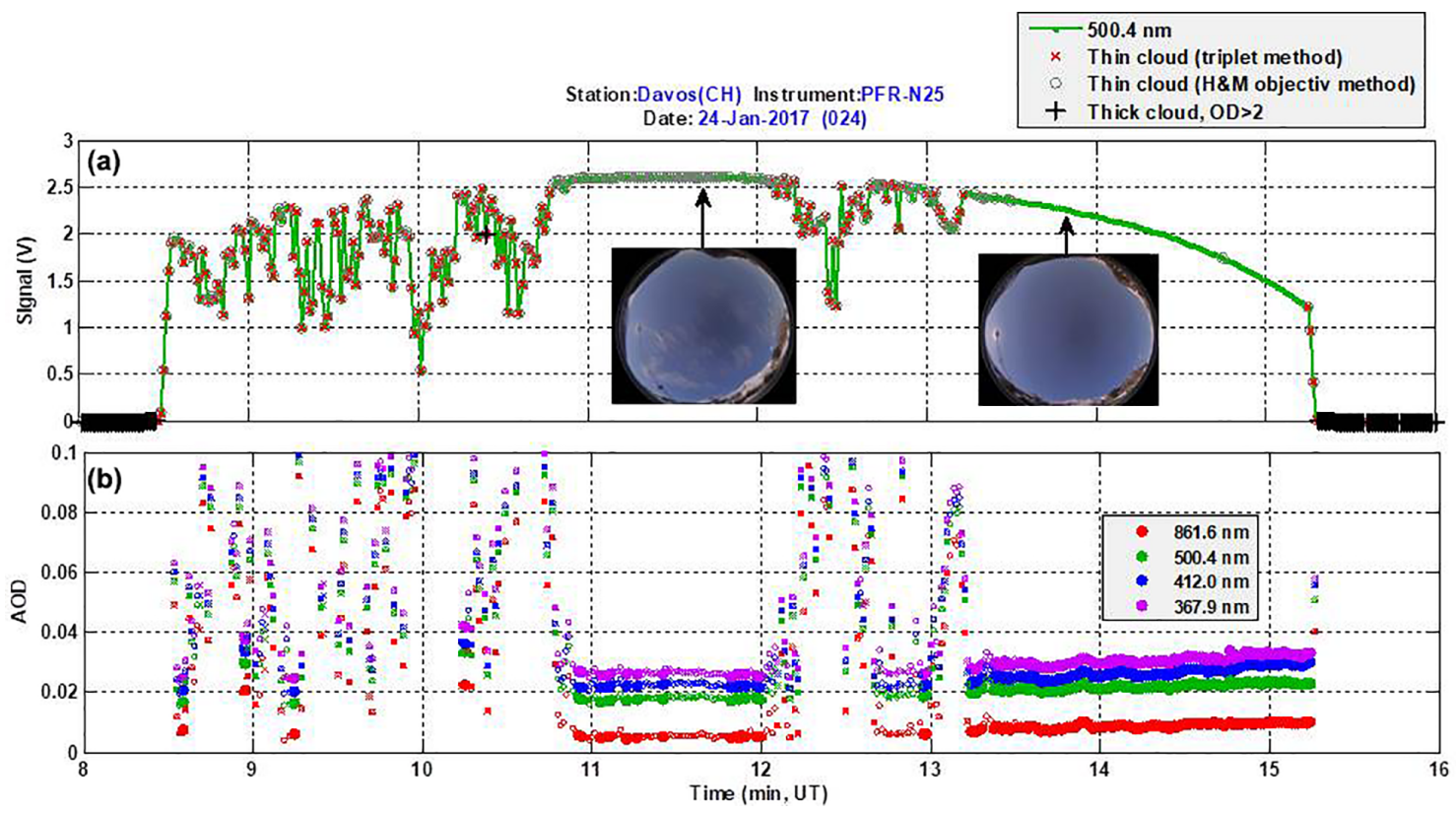

Figure 10. Example of a day with variable cloudiness, (a) instrument signal at $500 \mathrm{~nm}$ and minute-by-minute application of the three cloudflagging methods. The two inset pictures show a $360^{\circ}$ view of the sky using a cloud camera. (b) Calculation of AOD at four wavelengths. 


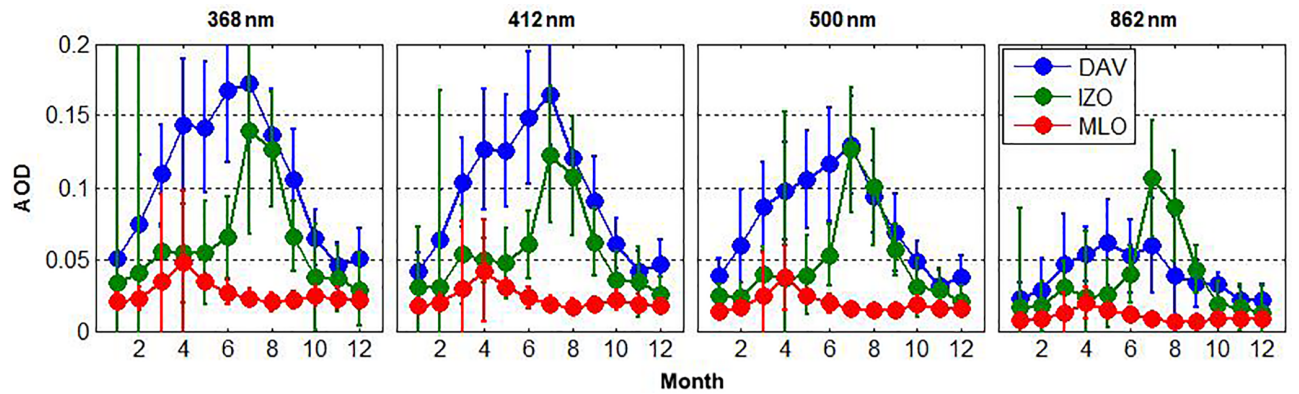

Figure 11. Monthly means and $1 \sigma$ standard deviations for Davos, Izaña and Mauna Loa using 15 years of 1 min quality-controlled PFR measurements at four wavelengths.

- A minimum of six 1 min cloud free measurements are required to calculate the hourly mean.

- A minimum of 30 hourly values and 10 days per month are required to calculate the monthly mean.

- Measurements that lie beyond 2 standard deviations for an hourly mean are considered outliers, as they are considered to be affected by cloud contamination.

Monthly statistics can be presented with different approaches. In most studies, AOD is usually reported as the arithmetic mean and associated standard deviations over a selected period. This is based on the hypothesis of an underlying normal distribution. However, AOD is often better characterized by a lognormal distribution and described by geometric mean and standard deviation. Based on a statistical analysis of skewness and kurtosis in a multiyear and multistation AOD data set, O'Neill and co-authors (O'Neill et al., 2000) have shown that a lognormal distribution systematically provides a more robust base for reporting AOD statistics than the normal distribution. Using long-term series of the final-selected $1 \mathrm{~min}$ AOD data, users can then try to draw conclusions on the AOD climatology of each station, the aerosol changes, if any, or the daily monthly and annual patterns. As an example of the three Langley calibrationrelated stations IZO, DAV and MLO, monthly means calculated from 15 years of measurements are presented in Fig. 11. IZO and MLO are the Langley calibration sites and DAV the triad host site.

For the particular sites that are all considered to have low AOD, we can clearly see that Davos shows an increase in AOD during the summer months, while the other two sites show much lower AOD with the exception of Saharan dust intrusions at Izaña for the July-September months.

When comparing MLO and IZO statistics, we calculate long-term $\mathrm{AOD}_{550}$ means of 0.050 and 0.020 , respectively, and geometrical means of 0.033 and 0.017 . Respective geometrical standard deviations are about 1.7 for MLO and 2.6 for IZO, meaning that AOD varies from 60 to $170 \%$ of 0.017 for MLO and from 38 to $260 \%$ of 0.033 for IZO. This is linked with the Saharan dust events (AOD outliers for a nor- mal distribution) that affect IZO. An overview of the GAWPFR AOD time series at all stations will be reported in a future study.

\section{Summary and conclusions}

"AOD is the single most comprehensive variable to assess the total aerosol load of the atmosphere and represents the least common denominator by which ground-based remote sensing, satellite retrievals and global modeling of aerosol properties are compared" (WMO, 2016a). According to the WMO, multiwavelength AOD is one of the essential variables that critically contributes to the characterization of Earth's climate. In addition, the Global Climate Observing System (GCOS) includes atmospheric aerosols including AOD as an essential climate variable. Finally, the European Space Agency has included aerosols and AOD as one of the 10 climate change initiative $(\mathrm{CCI})$ variables to be investigated with a view towards building space-based databases.

In order to monitor AOD over the long-term and provide data of traceable quality, the World Optical depth Research and Calibration Centre (WORCC), Davos, was established by the WMO Global Atmosphere Watch (GAW) program. Fifteen existing GAW baseline stations were chosen for the deployment of PFRs (precision filter radiometer; in-house manufacture). Quality-controlled and -assured AOD data from this GAW-PFR network (www.pmodwrc.ch/worcc) are being submitted by WORCC to the World Data Centre for Aerosols (ebas.nilu.no).

Under conditions of low aerosol loading, e.g., AOD $<0.1$ at $500 \mathrm{~nm}$, a calibration error of $1 \%$ results in an error of $\sim 12 \%$ in the mean daily AOD. WMO has recommended (WMO, 1993) an absolute limit to the estimated uncertainty of 0.02 optical depths for acceptable data and $<0.01$ as a goal to be achieved in the near future. These specifications require a calibration uncertainty better than $2 \%$ to be achieved for spectral radiometers. In addition, measurement quality control and quality assurance in different processing levels of the actual measured direct Sun signals or retrieved AOD have to be included. 
The calibration hierarchy of any network of Sun photometers is linked with the instrument performance and stability over time. Instruments which do not exhibit good stability (e.g., filter degradation) over time tend to utilize short periods for Langley calibrations where the instrument response can be considered constant. This can impact the calibration constant uncertainty through the limited number of measurements and the statistical analysis that is used. The PFR development and construction has been based on the use of specific hardware and manufacturing techniques that make them reliable for long-term measurements without rapid interference filter changes (e.g., Fig. 2). This provides the opportunity of using longer periods for collecting Langley calibration results and thus results in better statistics for the determination of the calibration constants.

Quality control of routine WORCC/PFR measurements includes a number of measurement-related checks, including the optical window cleanliness and the accuracy of the Sun pointing. In addition, a number of parameters such as pressure, ozone and $\mathrm{NO}_{2}$ concentrations have to be measured, assumed and/or modeled. Further QC procedures involve data evaluation, especially rejecting measurements with wavelength-related drifts (crossing) and suspected cloud contamination in the line of sight. Cloud screening becomes a difficult task, especially in the case of optically thin clouds that cannot be easily distinguished from AOD associated with coarse-mode aerosols. Finally, quality assurance of AOD data mainly include the determination of a proper calibration (extraterrestrial signals) within the required uncertainty.

WORCC has defined a protocol for calibrating the PFR instruments by maintaining a triad of reference PFRs that exhibit differences well within (more than $99 \%$ of $1 \mathrm{~min}$ data over a 12-year period) the U95 WMO criterion. The procedure includes systematic checks including comparisons with instruments that perform measurements (Langley calibrations) at high-altitude stations.

One of the aims of WORCC is the provision of instrumentation and protocols for uniform global measurement and records of AOD and the maintenance of the radiometric reference for such measurements. So in addition to the hosting and maintenance of the AOD triad, WORCC hosts the filter radiometer comparison every 5 years (e.g., WMO, 2016b) and maintains long-term AOD measurements at the main calibration sites of other aerosol networks such as AERONET (Mauna Loa, USA; Izaña, Spain) and SKYNET (Chiba, Japan; Valencia, Spain).

Data availability. The data that has been used in this work is available upon request.

Competing interests. The authors declare that they have no conflict of interest.
Acknowledgements. The authors would like acknowledge the Mauna Loa and Izaña Observatory staff for the inspection and in situ problem solving of the PFR instrumentation presented in this work. They would also like to thank the Scientific Advisory Group for Aerosols of the Global Atmospheric Watch, World Meteorological Organization Program, for the scientific support for WORCC.

Edited by: Mehrez Zribi

Reviewed by: Lionel Doppler and one anonymous referee

\section{References}

Angström, A.: On the atmospheric transmission of sun radiation and on dust in the air, Geografiska Annaler, 11, 156-166, 1929.

Barreto, A., Cuevas, E., Pallé, P., Romero, P. M., Guirado, C., Wehrli, C. J., and Almansa, F.: Recovering long-term aerosol optical depth series (1976-2012) from an astronomical potassiumbased resonance scattering spectrometer, Atmos. Meas. Tech., 7, 4103-4116, https://doi.org/10.5194/amt-7-4103-2014, 2014.

Bokoye, A. I., Royer, A., O'neill, N. T., Cliche, P., Fedosejevs, G., Teillet, P. M., and McArthur, L. J. B.: Characterization of atmospheric aerosols across Canada from a ground-based sunphotometer network: Aerocan, Atmos. Ocean., 39, 429-456, 2001.

Campanelli, M., Nakajima, T., and Olivieri, B.: Determination of the solar calibration constant a sun-sky radiometer: Proposal of an in situ procedure, Appl. Opt., 43, 651-659, 2004.

Che, H., Wang, Y., and Sun, J.: Aerosol optical properties at Mt. Waliguan Observatory, Chinga, Atmos. Environ., 45, 60046009, 2011.

Che, H., Zhang, X.-Y., Xia, X., Goloub, P., Holben, B., Zhao, H., Wang, Y., Zhang, X.-C., Wang, H., Blarel, L., Damiri, B., Zhang, R., Deng, X., Ma, Y., Wang, T., Geng, F., Qi, B., Zhu, J., Yu, J., Chen, Q., and Shi, G.: Ground-based aerosol climatology of China: aerosol optical depths from the China Aerosol Remote Sensing Network (CARSNET) 2002-2013, Atmos. Chem. Phys., 15, 7619-7652, https://doi.org/10.5194/acp15-7619-2015, 2015.

Dutton, E. G., Reddy, P., Ryan, S., and DeLuisi J. J.: Features and effects of aerosol optical depth observed ant Mauna Loa, Hawaii, 1982-1992, J. Geophys. Res., 99, 8295-8306, 1994.

Flowers, E. C., McCormick, R. A., and Kurfis, K. R.: Atmospheric Turbidity over United States, 1961-1966, J. Appl. Meteorol., 8, 955-962, 1969.

Goloub, P., Li, Z., Dubovik, O., Blarel, L., Podvin, T., Jankowiak, I., Lecoq, R., Deroo, C., Chatenet, B., Morel, J. P., Cuevas, E., and Ramos, R.: PHOTONS/AERONET sunphotometer network overview: description, activities, results, Proc. SPIE, 6936, 69360V, https://doi.org/10.1117/12.783171, 2007.

Harrison L., Michalsky, J., and Berndt, J.: Automated multifilter rotating shadow-band radiometer: an instrument for optical depth and radiation measurements, Appl. Opt., 33, 5118-5125, 1994.

Herber, A., Thomason, L. W., Gernandt, H., Leiterer, U., Nagel, D., Schulz, K. H., Kaptur, J., Albrecht, T., and Notholt, J.: Continuous day and night aerosol optical depth observations in the Arctic between 1991 and 1999, J. Geophys. Res., 107, 4097, https://doi.org/10.1029/2001JD000536, 2002. 
Holben, B. N., Eck, T. F., Slutsker, I., Tanre, D., Buis, J. P., Setzer, A., Vermote, E., Reagan, J. A., Kaufman, Y. J., Nakajima, T., Lavenu, F., Jankowiak, I., and Smirnov, S.: AERONET - A Federated Instrument Network and Data Archive for Aerosol Characterization, Remote Sens. Environ., 66, 1-16, 1998.

Holben, B. N., Tanré, D., Smirnov, A., Eck, T. F., Slutsker, I., Abuhassan, N., Newcomb, W. W., Schafer, J. S., Chatenet, B., Lavenu, F., Kaufman, Y. J., Vande Castle, J., Setzer, A., Markham, B., Clark, D., Frouin, R., Halthore, R., Karneli, A., O’Neill, N. T., Pietras, C., Pinker, R. T., Voss, K., and Zibordi, G.: An emerging ground-based aerosol climatology: Aerosol optical depth from AERONET, J. Geophys. Res., 106, 1206712097, 2001.

IPCC: climate change 2013: the physical science basis, edited by: Stocker, T. F., Qin, D., Plattner, G. K., Tignor, M., Allen, S. K., Boschung, J., Nauels, A., Xia, Y., Bex, B., and Midgley, B. M., Contribution of working group I to the fifth assessment report of the intergovernmental panel on climate change, 2013.

Junge, C.: Gesetzmässigkeiten in der Grössenverteilung atmosphärischer Aerosole über dem Kontinent, Berichte des Deutschen Wetterdienstes in der US-Zone, Nr. 35, 261-275, 1952.

Linke, F.: Die Sonnenstrahlung und ihre Schwächung in der Atmosphäre, Handbuch der Geophysik, 8, 239-338, 1942.

McArthur, L. J. B., Halliwell, D. H., Niebergall, O. J., O’Neill, N. T., Slusser, J. R., and Wehrli, C.: Field comparison of network photometers, J. Geophys. Res., 108, 4596, https://doi.org/10.1029/2002JD002964, 2003.

McPeters, R. D., Frith, S., and Labow, G. J.: OMI total column ozone: extending the long-term data record, Atmos. Meas. Tech., 8, 4845-4850, https://doi.org/10.5194/amt-8-4845-2015, 2015.

Mitchell, R. M., Forgan, B. W., and Campbell, S. K.: The Climatology of Australian Aerosol, Atmos. Chem. Phys., 17, 5131-5154, https://doi.org/10.5194/acp-17-5131-2017, 2017.

Michalsky, J. J., Schlemmer, J. A., Berkheiser, W. E., Berndt, J. L., Harrison, L. C., Laulainen, N. S., Larson, N. R., and Barnard, J. C.: Multiyear measurements of aerosol optical depth in the Atmospheric Radiation Measurement and Quantitative Links programs, J. Geophys. Res.-Atmos., 106, 12099-12107, 2001

Mulcahy, J. P., O'Dowd, C. D., and Jennings, S. G.: Aerosol optical depth in clean marine and continental northeast Atlantic air, J. Geophys. Res., 114, D20204, https://doi.org/10.1029/2009JD011992, 2009.

Nyeki, S., Halios, C. H., Baum, W., Eleftheriadis, K., Flentje, H., Gröbner, J., Vuilleumier, L., and Wehrli, C.: Ground-based aerosol optical depth trends at three high-altitude sites in Switzerland and southern Germany from 1995 to 2010, J. Geophys. Res., 117, D18202, https://doi.org/10.1029/2012JD017493, 2012.

Nyeki, S., Wehrli, C., Gröbner, J., Kouremeti, N., Wacker, S., Labuschagne, C., Mbatha, N., and Brunke, E.-G.: The GAWPFR aerosol optical depth network: The 2008-2013 time series at Cape Point Station, South Africa, J. Geophys. Res.-Atmos., 120, 5070-5084, https://doi.org/10.1002/2014JD022954, 2015.

O’Neill, N. T., Ignatov, A., Holben, B. N., and Eck, T. F.: The lognormal distribution as a reference for reporting aerosol optical depth statistics, Geophys. Res. Lett., 27, 3333-3336, 2000.

Ruckstuhl, C., Philipona, R., Behrens, K., Collaud Coen, M., Dürr, B., Heimo, A., Mätzler, C., Nyeki, S., Ohmura, A., Vuilleumier, L., Weller, M., Wehrli, C., and Zelenka, A.:
Aerosol and cloud effects on solar brightening and the recent rapid warming, Geophys. Res. Lett., 35, L12708, https://doi.org/10.1029/2008GL034228, 2008.

Smirnov, A., Holben, B. N., Eck, T. F., Dubovik, O., and Slutsker, I.: Cloud-screening and quality control algorithms for the AERONET database, Remote Sens. Environ., 30, 337-349, 2000.

Takamura, T. and Nakajima, T.: Overview of SKYNET and its activities, Opt. Pura Apl., 37, 3303-3308, 2004.

Toledano, C., Cachorro, V. E., Berjon, A., de Frutos, A. M., Fuertes, D., Gonzalez, R., Torres, B., Rodrigo, R., Bennouna, Y., Martin, L., and Guirado, C.: RIMA-AERONET network: long-term monitoring of aerosol properties, Opt. Pura Apl., 44, 629-633, 2011 .

Tomasi, C., Kokhanovsky, A. A., Lupi, A., Ritter, C., Smirnov, A., O’Neill, N. T., Stone, R. S., Holben, B. N., Nyeki, S., Wehrli, C., Stohl, A., Mazzola, M., Lanconelli, C., Vitale, V., Stebel, K., Aaltonen, V., de Leeuw, G., Rodriguez, E., Herber, A. B., Radionov, Zielinski, T., Petelski, T., Sakerin, S. M., Kabanov, D. M., Xue, Y., Mei, L., Istomina, L., Wagener, R., McArthur, B., Sobolewski, P. S., Kivi, R., Courcoux, Y., Larouche, P., Broccardo, S., and Piketh, S. J.: Aerosol remote sensing in polar regions, Earth Sci. Rev., 140, 108-157, https://doi.org/10.1016/j.earscirev.2014.11.001, 2015.

Volz, F.: Photometer mit Selen-Photoelement zur spektralen Messung der Sonnenstrahlung und zur Bestimmung der Wellenlängenabhängigkeit der Dunsttrübung, Arch. Met. Geoph. Biokl. B, 10, 100-131, 1959.

Volz, F.: Some results of turbidity networks, Tellus XXI, 5, 625630, 1969.

Wehrli, C.: Calibrations of filter radiometers for determination of atmospheric optical depths, Metrologia, 37, 419-422, 2000.

Wehrli, C.: Remote sensing of Aerosol Optical Depth in a Global surface network, available at: https://www.research-collection. ethz.ch/handle/20.500.11850/150574, 2008.

Weller, M. and Gericke, K.: Long-term observations of aerosol optical depths at the Meteorological Observatory Lindenberg, Meteorol. Z., 14, 651-662, https://doi.org/10.1127/09412948/2005/0070, 2005.

WMO/GAW: report No. 101, Report of the WMO workshop on the measurement of atmospheric optical depth and turbidity, (WMO TD No. 659), Chapter 4: Working Group Discussions - Sunphotometry, 4-5, 1993.

WMO/GAW: report No. 143, Global Atmosphere Watch measurements guide, WMO/TD- No. 1073, Chapter 3: Aerosol and Optical Depth, 33-49, 2001.

WMO/GAW: report No. 162, Experts Workshop on a Global Surface-based Network for Long Term Observations of Column Aerosol Optical Properties (WMO TD No. 1287), Chapter: GAWPFR: A Network of Aerosol Optical Depth Observations with Precision Filter Radiometers (from Christoph Wehrli, 3639), 153 pp., 2005.

WMO/GAW: report No. 227, WMO/GAW Aerosol Measurement Procedures, Guidelines and Recommendations, 2nd Edn., WMO- No. 1177, ISBN 978-92-63-11177-7, (WMO/TD- No. 1177), ISBN 978-92-63-11177-7, Chapter 7: Aerosol Optical Depth 60-67, 2016a.

WMO/GAW: Report No. 231, The Fourth WMO Filter Radiometer Comparison (FRC-IV), 2016b. 